\title{
Indexación primera mesada pensional Línea Jurisprudencial
}

\author{
María Daniela Gómez Polo \\ Libia Judith Tovar Estrella \\ Tutor - Dr. Germán Alfonso López Daza \\ Universidad Surcolombiana
}

\section{INTRODUCCIÓN}

El identificar las sub-reglas planteadas por la Corte Constitucional de Colombia a lo largo de su actuar que nos permitiera construir una línea jurisprudencial frente al derecho a la pensión, nos generó inicialmente algunas dificultades al momento de establecer una narración jurisprudencial concerniente a los pronunciamientos relevantes sobre el tema, debido a que las sentencias de la Corte Constitucional al respecto suman un gran número, sobre las cuales sería prácticamente imposible definir un línea jurisprudencial dentro del tiempo definido. Por esta razón, especificamos el tema a indexación de la primera mesada pensional, para hacer el análisis de los mandatos de la Corte Constitucional en comparación de los dados por la Corte Suprema de Justicia.

Al iniciar la tarea de cumplir con el objetivo general de la investigación, logramos darnos cuenta que la indexación como tal no es tratado por las Altas Cortes como un derecho fundamental propiamente dicho, sino que excepcionalmente, llegaría a serlo por conexidad con el derecho a la dignidad humana y al mínimo vital de los pensionados en Colombia. La revisión de las sentencias de la Corte Constitucional sobre el derecho a la indexación de la primera mesada pensional, nos llevó a identificar un total de cuarenta (40) sentencias que abarcan un periodo que va de 1994 a 2011. Sin embargo, la construcción de la línea jurisprudencial finalmente la realizamos con base en trece (13) de éstas, las cuales analizan problemas de exequibilidad o inexequibilidad de normas, como algunos artículos de la Ley 100 de 1993 (Sistema de Seguridad Social); es decir, sentencias tipo C, sentencias de Unificación de Jurisprudencia tipo SU y sentencias que resuelven problemas y hechos específicos de los colombianos respecto a la protección de derechos fundamentales vía acción de Tutela, es decir, Sentencias Tipo T.

\section{OBJETIVOS}




\section{General}

Analizar las decisiones tomadas en Colombia por la Corte Constitucional en comparación con las adoptadas por la Corte Suprema de Justicia, en relación a la indexación de la primera mesada pensional, con el fin de elaborar la línea jurisprudencial que dé respuesta al problema jurídico.

\section{Específicos}

- Identificar el choque jurídico presentado entre las Altas Cortes respecto al tema de la indexación en Colombia, así mismo Definir las reglas y subreglas fijadas por la Corte Constitucional.

- $\quad$ Definir el concepto de la indexación, indización o corrección monetaria adoptado por las Altas Cortes en Colombia.

- Establecer a partir de la última sentencia de la Corte Constitucional la aplicación de la técnica de la ingeniería de reversa, para comenzar con el análisis jurisprudencial.

- Identificar los tipos de sentencias que influyen en la representación de la línea jurisprudencial.

\section{DESARROLLO}

\section{ESCENARIOS CONSTITUCIONALES}

A.

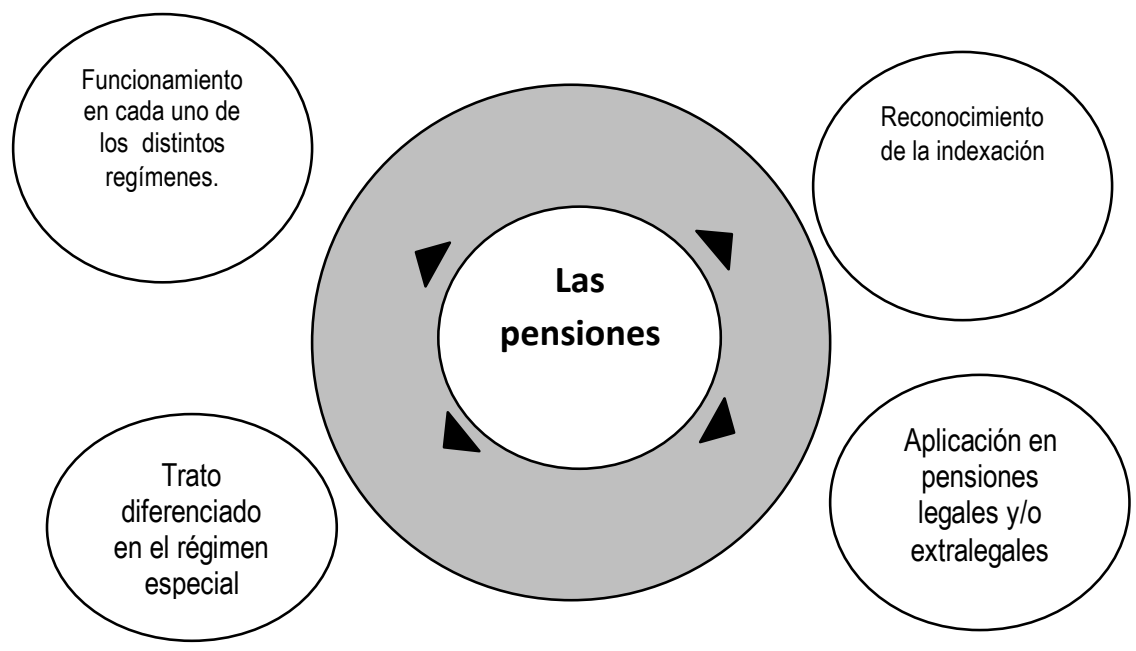


B.

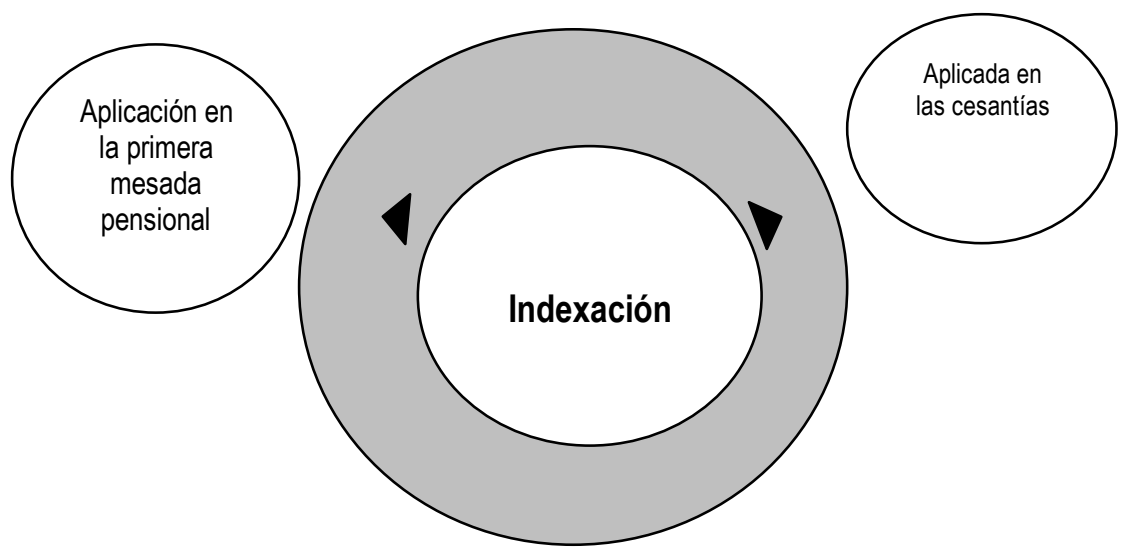

2. PROBLEMA JURÍDICO

¿Existe o no un derecho fundamental de los pensionados a mantener el poder adquisitivo constante de sus pensiones y por ende a la indexación de esta, teniendo en cuenta que existe un vacío normativo respecto al tema?

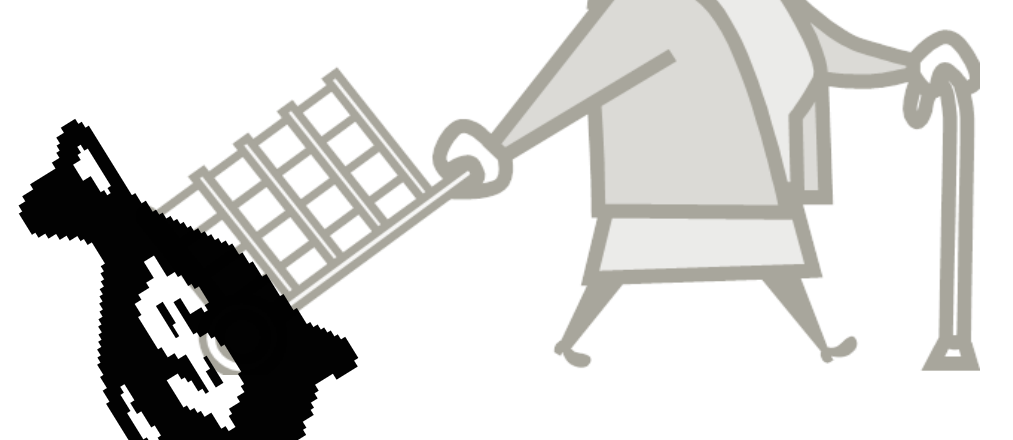


3. NICHO CITACIONAL

\begin{tabular}{|c|c|c|c|c|c|c|}
\hline $\mathbf{1 9 9 4}$ & $\mathbf{1 9 9 5}$ & $\mathbf{1 9 9 6}$ & $\mathbf{1 9 9 7}$ & $\mathbf{1 9 9 9}$ & $\mathbf{2 0 0 3}$ & $\mathbf{2 0 0 4}$ \\
\hline$\underline{{ }^{*} \mathrm{C}-260}$ & $\underline{\mathrm{C}-387}$ & $\underline{\mathrm{C}-448}$ & $\mathrm{C}-155$ & $\mathrm{C}-067$ & $\underline{\mathrm{SU}-120}$ & $\underline{\mathrm{T}-606}$ \\
& & & & $\mathrm{~T}-107$ & $\underline{\mathrm{T}-663}$ & $\mathrm{~T}-805$ \\
\hline $\mathbf{2 0 0 5}$ & $\mathbf{2 0 0 6}$ & $\mathbf{2 0 0 7}$ & $\mathbf{2 0 0 8}$ & $\mathbf{2 0 0 9}$ & $\mathbf{2 0 1 0}$ & $\mathbf{2 0 1 1}$ \\
\hline $\mathrm{T}-098$ & $\mathrm{C}-530$ & $\mathrm{~T}-224$ & $\mathrm{~T}-014$ & $\mathrm{~T}-187$ & $\mathrm{~T}-250$ & $\underline{\mathrm{T}-020}$ \\
$\mathrm{~T}-469$ & $\underline{\mathrm{C}-862}$ & $\mathrm{~T}-696$ & $\mathrm{~T}-089$ & $\mathrm{~T}-139$ & $\mathrm{~T}-362$ & \\
$\mathrm{~T}-906$ & $\mathrm{~T}-862$ & $\mathrm{~T}-1059$ & $\mathrm{~T}-311$ & $\mathrm{~T}-457$ & $\mathrm{~T}-621$ & \\
& $\mathrm{C}-891 \mathrm{~A}$ & & $\mathrm{C}-862$ & $\mathrm{~T}-906$ & & \\
& & & $\mathrm{~T}-897$ & & & \\
& & & $\underline{T}-1052$ & & & \\
\hline
\end{tabular}

*Sentencia que no está incluida en la Ingienería de Reversa. Sin embargo, inicialmente fue importante para establecer la dirección de la línea jurisprudencial.

_ Sentencias claves en la consolidaciónm de la línea jurisprudencial. 


\section{INGIENERIA DE REVERSA Y PUNTO ARQUIMÉDICO}

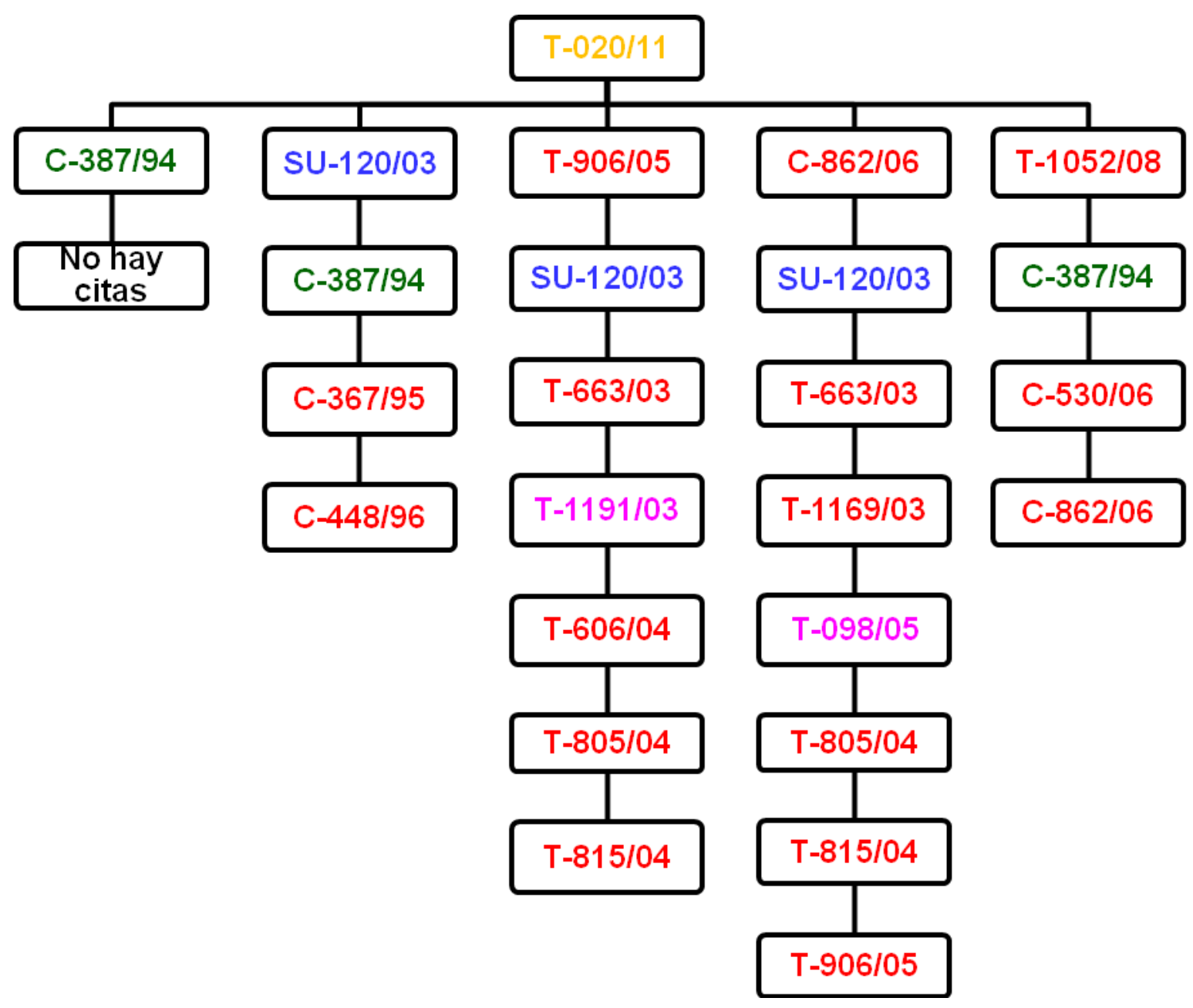

— Sentencias fundadoras de línea.

- Sentencia arquimédica.

- Sentencias hito, consolidadora de línea.

- Sentencias confirmadora de principio.

— Sentencias reconceptualizadoras de línea. 
5. BALANCE JURISPRUDENCIAL

\begin{tabular}{|c|c|c|}
\hline \multicolumn{3}{|c|}{$\begin{array}{c}\text { ¿Existe o no un derecho fundamental de los pensionados a mantener } \\
\text { el poder adquisitivo constante de sus pensiones y por ende a la } \\
\text { indexación de esta, teniendo en cuenta que existe un vacío normativo } \\
\text { respecto al tema? }\end{array}$} \\
\hline $\begin{array}{c}\text { El derecho a } \\
\text { mantener el } \\
\text { poder } \\
\text { adquisitivo de } \\
\text { las pensiones } \\
\text { es un derecho } \\
\text { funadamental } \\
\text { por conexidad } \\
\text { con el derecho } \\
\text { a la diginidad } \\
\text { humana, } \\
\text { razón por la } \\
\text { cual al negar } \\
\text { la indexación } \\
\text { so pretexto de } \\
\text { existir un } \\
\text { vacío } \\
\text { normativo éste } \\
\text { se estaría } \\
\text { violando. }\end{array}$ & 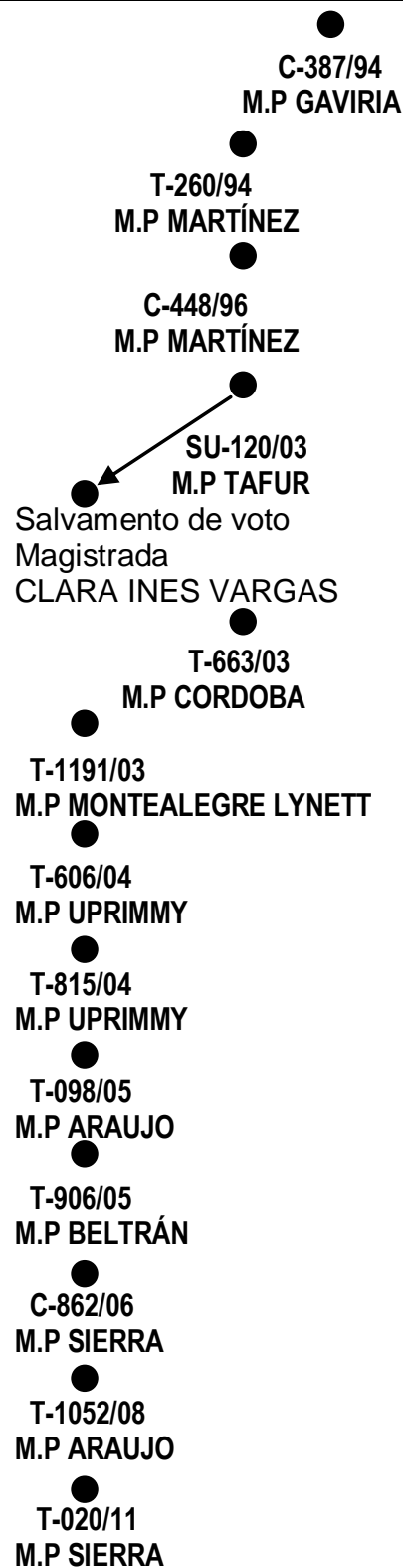 & $\begin{array}{c}\text { El derecho a } \\
\text { mantener el } \\
\text { poder } \\
\text { adquisitivo de } \\
\text { las pensiones } \\
\text { no es un } \\
\text { derecho } \\
\text { fundamental, } \\
\text { razón por la cual } \\
\text { al negar la } \\
\text { indexación de } \\
\text { éste, no se } \\
\text { violaría derecho } \\
\text { fundamental } \\
\text { alguno. } \\
\text { Siendo el } \\
\text { argumento clave } \\
\text { el vacío } \\
\text { normativo } \\
\text { existente } \\
\text { respecto al } \\
\text { tema. }\end{array}$ \\
\hline
\end{tabular}




\section{SOMBRA DECISIONAL}

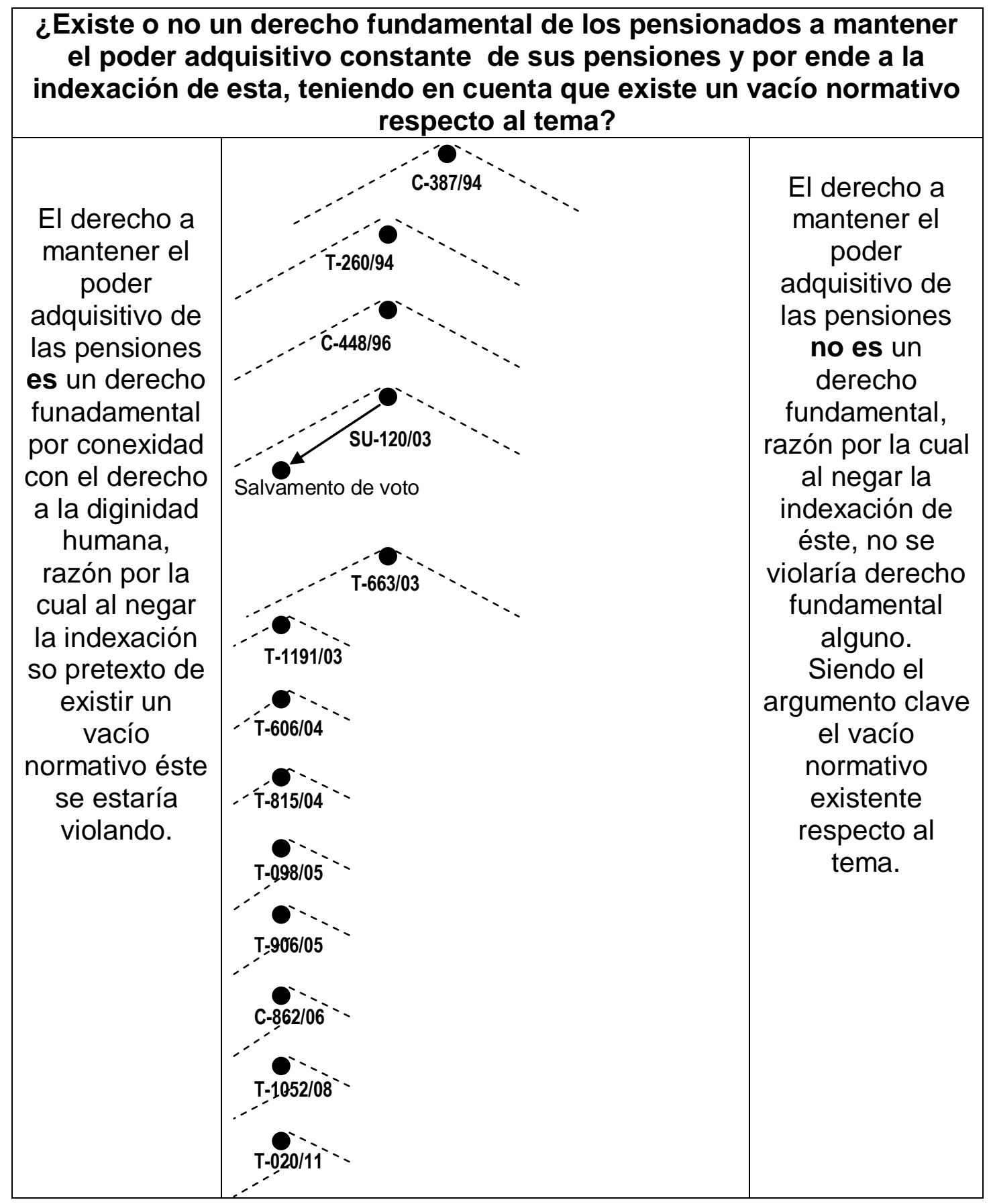




\section{TELARAÑA JURISPRUDENCIAL}

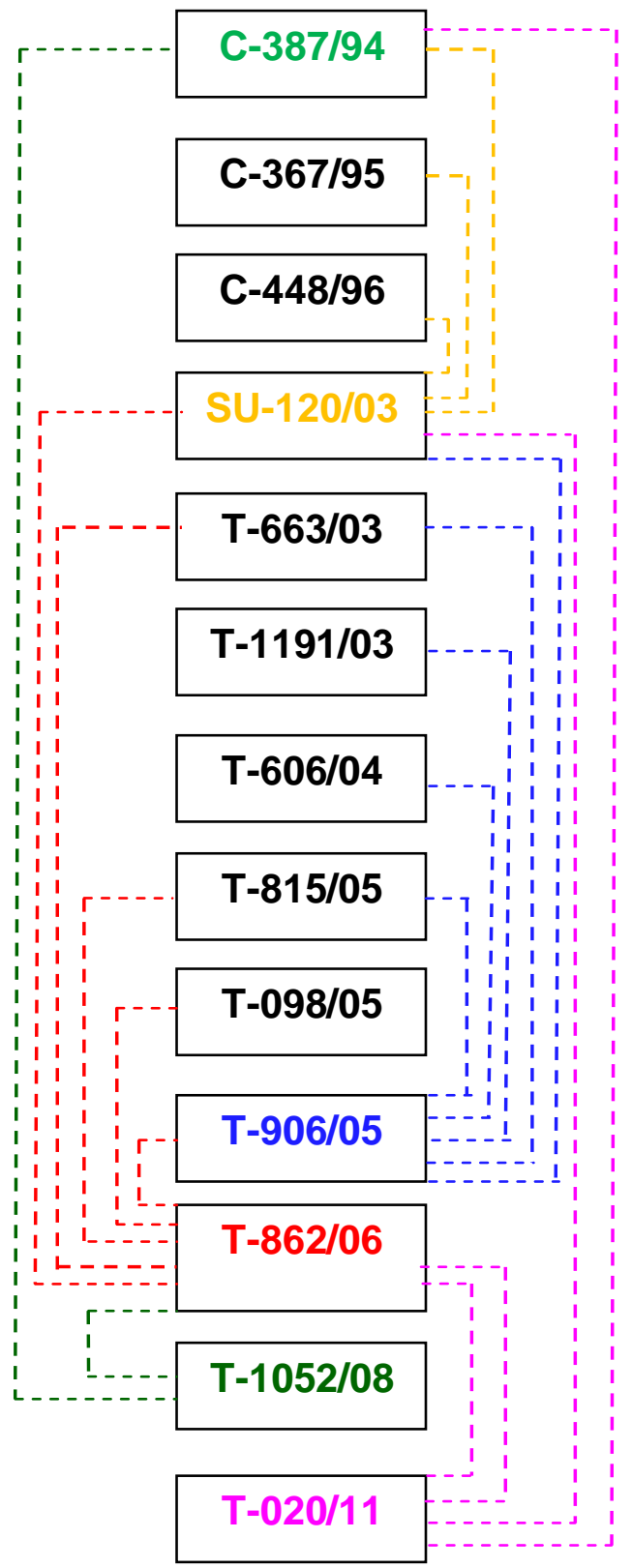




\section{NARRACIÓN DEL DESARROLLO JURISPRUDENCIAL}

\subsection{Marco legal histórico}

Han sido varias las leyes que han tratado de darle una imagen y tratamiento claro a la figura de la indexación, ya que un aspecto tan importante no fue consagrado inicialmente en el Código Sustantivo del Trabajo. Prueba de ello son decretos como el 678 y 1229 de 1972, donde por medio de las cuales el Estado buscaba amparar el derecho de los colombianos jubilados a mantener el poder adquisitivo de sus pensiones, pues en Colombia es posible evidenciar una desvalorización del dinero causada por algunos desequilibrios, como es el fenómeno de la inflación, aunque estos intentos resultarán siendo poco congruentes.

Además, el tema de la indexación se encuentra inmerso dentro del marco de Seguridad Social, consagrado en los artículos superiores 48 y 53 de la Constitución Política del 91, donde en el primero se declara que dicho Sistema es un servicio público bajo el control del Estado, pero que también puede ser prestado por entidades privadas; y en su inciso último y siendo el tema que nos atañe en esta oportunidad, expone que la ley es la encargada de definir los medios para que los recursos destinados a las pensiones mantengan su poder adquisitivo constante. El Acto Legislativo 01 del 2005, adicionó al art. 48 superior algunos enunciados que buscan sostener financieramente el Sistema, fija los requisitos para recibir la pensión, y además, realiza algunas modificaciones a los regímenes especiales, entre otros aspectos; observándose que esta excesiva reglamentación, conlleva a la denominada hiperconstitucionalización del derecho.

De igual manera, el artículo 53 superior trata acerca de la reglamentación del estatuto del trabajo y en su inciso segundo expresa: "El estado garantiza el derecho al pago oportuno y al reajuste periódico de las pensiones legales"; estos artículos de la Constitución se han convertido en un salvavidas para los pensionados en Colombia quienes procuran la defensa de sus derechos.

Dos años después, el poder adquisitivo de las pensiones fue estudiado en el régimen de transición adoptado en la Ley 100 de 1993, la cual regula el Sistema de Seguridad Social en Salud, Riesgos Profesionales y las Pensiones basada en los principios de eficiencia, universalidad y solidaridad, cuyos objetivos preliminares eran los de garantizar las prestaciones económicas y de salud a quienes tienen una relación laboral o capacidad económica suficiente para afiliarse al sistema. Su aparición en el contexto del país enamoró a un gran número de personas, quienes creían que su aplicación sería acorde a su contenido filosófico. Sin embargo, en el país es sentida la situación de exclusión y barreras de acceso a la atención en seguridad social generada por la puesta en marcha de dicha Ley.

\subsection{Recuento jurisprudencial}

En 1992 y 1993 la Corte Constitucional no se pronunció sobre la indexación, viene a hacerlo tan sólo a partir de 1994 como resultado de las inconformidades en 
contra de la Ley 100 de 1993. Reflejo de ello son algunas demandas de inconstitucionalidad instauradas por parte de los ciudadanos contra dicha ley, como la que es analizada en la sentencia C-387 donde se demanda su artículo 14 parcialmente. Esta sentencia, como la fundadora de línea, abre las puertas para que más adelante sea posible que los pensionados puedan acceder a la corrección monetaria o indexación de su primera mesada pensional.

Como parte de sus argumentos, el demandante asegura que el artículo 14 de la Ley 100 , genera cierta inferioridad entre las personas que únicamente reciben un salario mínimo y las que devengan más de uno, debido a que el reajuste de la pensión es realizado teniendo en cuenta el incremento del IPC. Sin embargo, la Corte con base en estudios económicos, afirma que estos aumentos no van a ser iguales todos los años, pues la situación económica del país fluctúa debido a variantes internas y externas que interfieren en el contexto de la región. Razón por la que la Corte Constitucional resuelve declarar el artículo exequible pero de manera condicionada, afirmando que: "En el caso de que la variación porcentual del índice de Precios al Consumidor, certificado por el DANE, para el año inmediatamente anterior a aquél en que se vaya a efectuar el reajuste de las pensiones, sea superior al porcentaje en que se incremente el salario Mínimo Mensual, las personas cuya pensión sea igual al salario Mínimo Mensual Vigente tendrán derecho a que ésta se les aumente conforme a tal índice" (Sentencia C-387, 1994).

Al interior de la Corte Constitucional por primera vez se reconoce la indexación y la importancia de la pensión como el resultado de una relación valor -trabajo, es decir, que al no dar cumplimiento de ésta, se estaría desconociendo el trabajo del empleado, lo que en un futuro afectaría su patrimonio dado que con el pasar de los años es inminente una devaluación de la moneda y el dinero sería insuficiente para que el empleado viva dignamente, como es el querer de nuestra sociedad expresado en la Constitución Política.

A pesar del reconocimiento de la indexación en materia pensional, un año después en la C-367, se evidencia el vacío normativo en Colombia respecto al tema, ratificado en distintas ocasiones por la misma Corte Constitucional; en esta sentencia la Corte reconoce que los pensionados tienen derecho a que se les indemnice por el pago tardío de su mesada pensional aunque no exista una regulación específica acerca de la corrección monetaria, que medie y que brinde una herramienta efectiva para garantizar sus derechos ya adquiridos. También establece que la obligación de llevar a cabo la corrección monetaria es ineludible, pues sería injusto que la persona afectada por la pérdida del poder adquisitivo de la moneda, además, deba tolerar que ésta no le sea indexada. Es por ello que la Corte hace énfasis en la obligatoriedad de la doctrina constitucional fijada por ella, la cual se encuentra establecida a favor de la indexación de la primera mesada pensional sin necesidad de requerimiento judicial, aunque hay lugar a obtener el pago coercitivamente, fijando el alcance del artículo 53 de la Constitución Política. Esta noción no es reciente, pues la Corte Suprema de Justicia ya había 
contemplado este reconocimiento en algunas de sus sentencias (Uribe Restrepo, 1982 y 1988).

El concepto de la indexación fue dado por la Corte Constitucional en la sentencia C-448 de 1996 como: "una simple actualización de una obligación dineraria con el fin de proteger el poder adquisitivo de los trabajadores debido a los fenómenos inflacionarios". En esta sentencia se reafirma lo ya establecido por la Corte Suprema de Justicia:

"La indexación o corrección monetaria en relación con aquellas prestaciones que no tengan otro tipo de compensación de perjuicios por la mora o que no reciban reajuste en relación con el costo de vida, conforme a lo dicho antes, pues es obvio que de no ser así el trabajador estaría afectado en sus ingresos patrimoniales al recibir al cabo del tiempo el pago de una obligación en cantidad que resulta en la mayoría de las veces irrisoria por la permanente devaluación de la moneda en nuestro país originándose de esa manera el rompimiento de la coordinación o "equilibrio" económico entre empleadores y trabajadores que es uno de los fines primordiales del derecho del trabajo" Tomado de la Sala Laboral, Corte suprema de Justicia, Sentencia de 20 de mayo de 1992. Criterio acogido por la Corte Constitucional en las sentencias T-260/94 y T-102/95.

Según las consideraciones anteriores, podría deducirse la unificación de la misma línea jurisprudencial no sólo de la Corte Constitucional sino también en asociación con la Corte Suprema de Justicia ya que ambas acceden a la indexación como un correctivo en la depreciación que puede presentar la pensión en el transcurso del tiempo; sin embargo, en los años posteriores la Corte Suprema de Justicia en su Sala de Casación Laboral decide cambiar su propio precedente, según la Corte Constitucional sin la carga argumentativa suficiente, llegándose a generar lo que se conoce coloquialmente como el "choque de trenes" entre las Altas Cortes en Colombia y por ende, creándose una inseguridad jurídica para las personas afectadas.

Dada la anterior situación, es necesario dividir nuestro problema jurídico en dos partes para encontrarle solución: la primera, es establecer si para la Corte Constitucional existe o no una violación al derecho del pensionado de mantener el poder adquisitivo constante de su pensión cuando no accede a la respectiva indexación, so pretexto de existir un vacío normativo, como lo indica la Sala Laboral de la Corte Suprema de Justicia; es cierto que este análisis se planteó inicialmente con el fin general de estudiar las decisiones de la Corte Constitucional, sin embargo, es necesario conocer igualmente los pronunciamientos de la Corte Suprema de Justicia, ya que al distanciarse las unas de las otras, se genera una total inseguridad jurídica al respecto e incertidumbres para los afectados; en segundo lugar, es discutir un asunto que antes de la sentencia SU-120 de 2003 (unificadora de línea) no había presentado 
mayor discusión, pero luego se muestra como el único argumento con el cual la Corte Constitucional posteriormente va a negar la indexación de la primera mesada pensional, hace referencia así, el derecho a mantener el poder adquisitivo constante y por ende la indexación, que puede ser considerado como un derecho fundamental. Es preciso aclarar que aunque ambas posturas podrían plantearse de manera separada, la trascendencia y dependencia una de la otra nos lleva a analizarlas en conjunto.

\subsubsection{Vacío normativo respecto a la indexación pensional}

Como consecuencia de la modificación de la línea jurisprudencial de la Sala Laboral de la Corte Suprema de Justicia, se presentaron tutelas en una cantidad considerable contra las sentencias proferidas por la misma, ante la Corte Constitucional, siendo ésta la llamada a amparar los derechos fundamentales, pues según los accionistas era ilógico el que la Corte Suprema de Justicia desconociera su propio precedente al negar la indexación de la primera mesada pensional. Este suceso fue ampliamente tratado en la sentencia SU-120 de 2003, la cual pretendía unificar las decisiones y dar mayor seguridad jurídica a los afectados por dicha situación. Para comprender su alcance, se hace necesario realizar un recuento de las decisiones emitidas por la Corte Suprema de Justicia, los argumentos de las Cortes para sostener su decisión y sus implicaciones para casos futuros:

a) Decisiones emitidas por la Corte Suprema de Justicia (antecedentes)

- Sentencia de 18 de agosto de 1982: la Sección Primera, sostiene que del trabajo depende la vida de las personas y que éste se ve afectado por la inflación, sin embargo, afirma que la estimulación por parte de la ley y por la jurisprudencia ha sido casi inexistente.

- Sentencia de 11 de abril de 1987: la Sección Segunda de la misma corporación sostuvo que no era posible su aplicación respecto de las deudas laborales, como forma de compensar los perjuicios al acreedor, por no existir texto legal que así lo consagre (vacío normativo al respecto)

- Sentencia del 8 de abril de 1991: la Sección Segunda, sostuvo que la indexación era una modalidad del daño emergente y que, debía ser incluida para que la satisfacción de la obligación fuera completa. Con esta decisión, ambas secciones adoptan una postura unificada respecto a la indexación.

- El desvío jurisprudencial se hizo evidente a partir del año de 1999, explícitamente en dos sentencias: la primera, del 31 de agosto, que establece que si las partes no pactaban la indexación, no le correspondía al juez imponerla, basados en que en este caso no se violaba ningún derecho del trabajador, por tanto se respetaba el valor mínimo de la mesada pensional fijado por la ley; y la segunda, sentencia del 14 de septiembre, se consigna que el cambio jurisprudencial obedeció a la modificación de la composición de la Sala, así como también que la pérdida de poder adquisitivo 
del salario base no es una carga que deba asumir el empleador, la cual afecta su capacidad económica. Sostiene también que si la ley no señala ningún tipo de actualización, no hay lugar a reconocerla jurisprudencialmente, según lo introducido por la Ley 100 de 1993.

b) Argumentos de la Corte Suprema de Justicia para respaldar su cambio de jurisprudencia:

- Cambio en la conformación de la Sala Laboral, ya que los nuevos integrantes tenían una visión distinta del tema y disponían de otros argumentos sólidos y válidos para cambiar el precedente sentado por los anteriores magistrados.

- En nuestro país existe un vacío normativo, casi total, sobre la indexación, debido al corte nominalista del ordenamiento jurídico, que se ha establecido con el propósito de restablecer el equilibrio perdido en las relaciones contractuales, de igual manera los mecanismos que trae inmersos la ley 100 de 1993 para liquidar la pensión, no se puede aplicar de manera retroactiva.

- La Corte alega que aunque su decisión de acceder a la indexación fue reiterada más de tres veces, puede ser desconocida por ella misma, pues sólo constituye la doctrina legal más probable. Además, cuando se aceptó por mayoría de la Sala de Casación Laboral la corrección monetaria, se puso siempre de presente que la obligación dineraria no procedía cuando existiera cualquier otro mecanismo mediante el cual se lograra compensar esta pérdida del poder adquisitivo de la moneda; aparte que los supuestos de hecho varían de una demanda a otra, de manera que no se puede pretender dictar una única sentencia, pues se estaría volviendo al derecho inmodificable.

- Las obligaciones contractuales no se indemnizan en tanto acreedor y deudor han tenido la oportunidad de pactar mecanismos en contra de la inflación, y es por ello que el juez no puede interferir en este proceso.

- No se indexan las obligaciones eventuales, es decir, en condición de suspensión, ya que esta se adquiere con dos requisitos: la edad y el tiempo exigido. Tales requisitos no se advierten en la sentencia SU-120 de 2003, pues sólo se indexan las obligaciones cuya fuente es la ley y no es necesario acudir a la analogía ni a la equidad para ordenar esa indexación, así mismo ésta no tiene alcance general, es una medida excepcional que el legislador la ha establecido para casos particulares, únicamente como medio correctivo a las situaciones de pago retardado de algunos créditos.

- El nuevo fallo de la Corte no afecta los intereses de los demandantes, pues incluso antes de la ley 100 de 1993 se estableció que ninguna pensión puede ser inferior al Salario Mínimo Legal Vigente Mensual, con esto se asegura el sustento del pensionado.

c) Argumentos de la Corte Constitucional para desvirtuar la actuación de la Corte Suprema de Justicia:

- Los jueces deben seguir el precedente y con más razón cuando es propio, de lo contrario se originaría una inseguridad jurídica y anarquía en el tema laboral. 
- El cambio de conformación de la Corte Suprema, no es motivo para un cambio tan radical de jurisprudencia, ya que ésta no contaba con la aceptación de todos los magistrados, situación que se vio reflejada en los salvamentos de voto que suscitó dicha decisión.

- La Corte Suprema de Justicia debe unificar la jurisprudencia nacional pero no puede introducir modificaciones sin la debida justificación, sin tener en cuenta los cambios sociales, políticos o económicos pertinentes, ya que estaría en contra de los intereses de los demandantes, los derechos de favorabilidad e igual de trato, además implicaría una contradicción con el principio de colaboración armónica entre las ramas del poder.

- Los acuerdos celebrados en los contratos deben sujetarse a la indexación también.

- La Corte Suprema de Justicia cae en un grave error al no acceder a la indexación de la primera mesada pensional, porque de no hacerlo, la inflación como hecho notorio terminaría afectando gravemente al trabajador, estando en contra de la equidad, ya que él no cuenta con los medios necesarios para soportar este fenómeno económico

- La corrección monetaria sólo puede ordenarse para corregir el daño emergente causado por el incumplimiento de obligaciones laborales, no obstante con la ley 100 de 1993, se precisó que no existe razón válida para negar a los pensionados la indexación de su primera mesada pensional.

d) Es interesante la situación que se presentó en esta sentencia SU-120/2003, pues aunque este análisis estaba planteado primordialmente a examinar las decisiones emitidas por la Corte Constitucional en el tema de la indexación, en el transcurso del mismo, surgió un nuevo interrogante, como anteriormente se había mencionado: el "choque de trenes" entre las Altas Cortes a partir de las posiciones diferentes que adoptaron a partir de 1999, con el fallo de la Sala de Casación Laboral en contra de la indexación. Se ha llevado a cabo un recuento de las decisiones y expuesto los argumentos de las Cortes que dan fundamento a sus decisiones, la más trascendental de ellas es el vacío normativo frente a la indexación, concepción que ha tratado de desvirtuar la Corte Constitucional quien argumenta que si bien no existe norma explícita, se debe acudir a la analogía y a aplicar lo dicho en los artículos 48 y 53 de la Carta Política, los cuales amparan al trabajador para que sus pensiones no pierdan poder adquisitivo con el paso del tiempo y mantengan su valor, en últimas, este es el fin de la indexación. De esta manera, la Corte Constitucional en la sentencia SU-120 de 2003, expuso: i) que no existe normatividad que establezca con precisión la base para liquidar la pensión de jubilación de quien se retire o sea retirado del servicio sin cumplir la edad requerida -el inciso segundo del artículo 260 del C.S.T, derogado expresamente por el artículo 289 de la Ley 100 de 1993 pero aplicable a los casos en que hubo reconocimiento de la pensión antes de la vigencia de éste último, no la precisa-; ii) que ninguna disposición ordena expresamente indexar esta base salarial; iii) que no existe precepto que excluya o prohíba tal indexación.

No obstante -concluyó la Corte-, existe un principio constitucional claro, esto es que el "Estado garantiza el derecho al pago oportuno y al reajuste periódico de las pensiones legales" -artículo 53 C.P.- y suficientes disposiciones del ordenamiento 
que denotan un afán permanente del legislador por compensar la pérdida del poder adquisitivo de las pensiones. En este orden de ideas, -consideró- que es de incumbencia del juez evaluar la situación concreta de las personas que aspiran a acceder a la pensión en las condiciones anotadas y remediar la injusticia que se deriva de la omisión normativa anotada, obrando en todo conforme lo habría hecho el legislador, de haber considerado la situación específica, es decir conforme con la Constitución Política" (Sentencia SU-120, 2003).

Es así como en la parte resolutiva de la sentencia SU-120 de 2003, la Corte Constitucional ordena a la Sala de Casación Laboral de la Corte Suprema de Justicia revisar nuevamente el caso de los demandantes y resolver el problema según el alcance de la indexación fijado en esta sentencia. De esta manera queda resuelto el primer punto del problema jurídico, mencionado anteriormente.

Siguiendo con el recuento jurisprudencial, en el mismo año se resuelve la sentencia T-663 en la cual se confirma la nueva línea jurisprudencial sentada anteriormente en la SU-120/03. Al respecto, la Corte Constitucional expresa nuevamente que aunque existe una omisión normativa para regular la indexación, es el juez quien debe remediar esta injusticia en contra del pensionado, pues la Constitución le ha conferido facultades para rechazar situaciones que le sean desfavorables al trabajador (art. 48 y 53 C.P). Del mismo modo hace alusión a las decisiones no uniformes emitidas por la Sala Laboral de la Corte Suprema de Justicia, las cuales en primer lugar aceptaban la indexación por los mismos argumentos de la Corte Constitucional, pero posteriormente la negaba pues la mediación del juez interfería con la labor del legislador. En conclusión, la Corte reafirma su propio precedente.

\subsection{2 ¿Derecho fundamental?}

El segundo punto del problema jurídico que hace referencia a si el derecho a mantener el poder adquisitivo constante y por ende la indexación, puede ser considerado o no como un derecho fundamental.

Posteriormente en la sentencia T-1191 de 2003, se da un caso interesante, donde se estudian asuntos de fondo que antes no se habían tenido en cuenta en la sentencia SU-120/03, de gran relevancia para casos posteriores. En la primera sentencia se define que el derecho a mantener el poder adquisitivo de las pensiones, y por ende la indexación, es un derecho de rango constitucional, circunstancia que está expresamente consagrada en los artículos 48 y 53 de la Constitución Política y no puede ser considerado como un derecho fundamental autónomo porque no tiene carácter universal, ni tampoco existe norma explicita constitucional que así lo diga.

Sin embargo, más adelante la Corte Constitucional hace una enmienda respecto a lo mencionado anteriormente, estableciendo una nueva subregla en el tema de la indexación; es importante en la medida que establece la acción de tutela para reclamar la indexación, no considerado derecho fundamental autónomo, pero si por conexidad con la dignidad humana cuando la persona sobrepase los 71 años, pues cuenta con prioridad. Este mismo asunto fue abordado en un salvamento de voto de la sentencia SU-120/03, en donde la magistrada aludía que la Corte no 
había establecido claramente si existe un derecho fundamental a la indexación, creando incertidumbre tanto para los pensionados como para los jueces. Al respecto la Corte ha dicho:

"no desconocemos que el derecho a mantener el poder adquisitivo de las pensiones puede llegar a considerarse excepcionalmente como un derecho fundamental por conexidad...esto ocurre, por ejemplo, cuando se rompe de manera abrupta la proporción entre el valor histórico de la pensión y su valor actual y esta circunstancia tiene como consecuencia la afectación del derecho al mínimo vital, a partir de una valoración de mínimo patrimonial. Es decir cuando la mesada pensional ha sufrido una depreciación tan insoportable que negar el derecho a mantener el poder adquisitivo de la pensión, amenaza las condiciones de subsistencia del titular del derecho prestacional." (Sentencia T-1191, 2003).

Esta sentencia es un caso poco frecuente porque la Corte no accede a indexar la primera mesada pensional de la solicitante, pero no porque desconozca su propio precedente fijado en la SU-120/03, sino porque los hechos entre ambos pronunciamientos no son iguales, por ello el resultado es distinto.

En el año 2004 en la sentencia T-606, no se tiene en cuenta el precedente fijado por la sentencia SU-120/03, ya que en ella los solicitantes agotaron todas las instancias respectivas, supuesto que en el caso concreto no se presenta. Además, la Corte reconoce que para la época en que se solicitó la indexación no existía una jurisprudencia unificada al respecto, dadas las contradicciones entre las decisiones proferidas por la Corte Constitucional y la Sala de Casación Laboral de la Corte Suprema de Justicia. Es necesario reiterar que en este fallo, así como en la sentencia T-1191 de 2003, no se indexan las pensiones no porque se desconozca el precedente, sino por otras situaciones que surgen en el transcurso del proceso y las diferencias entre los supuestos fácticos.

También es pertinente mencionar la sentencia T-815/04, en la cual se hace un recuento jurisprudencial y reitera lo dicho en la sentencia SU-120/03 la cual unifica los fallos en el tema de la indexación de la primera mesada pensional, de igual manera hace alusión a las sentencias confirmadoras de principio, las cuales hacen énfasis en estudiar la necesidad de mantener el valor adquisitivo de las pensiones dada la depreciación que sufre la moneda debido a efectos económicos como la inflación que no se pueden evitar y que generan una situación negativa para el pensionado, ya que ve reducido su capital y afecta su poder de adquisición de alimentos o materiales para vivir dignamente; así mismo debe existir un equilibrio en las relaciones de trabajo, situación que no puede ser desconocida por ningún juez ordinario, pues de lo contrario, se hará necesaria la intervención del juez constitucional quien debe subsanar el vacío dejado por el legislador en materia de indexación y amparar los derechos que se le estén violando al pensionado en calidad de tal. Pero también advierte la Corte, que el primer paso es agotar todos los medios ordinarios y laborales antes de interponer la acción de tutela, pues de lo contrario esta no será aceptada. (sentencias T-1191, 2003 y T-603, 2004). 
Así mismo, la Corte señala en la sentencia T-098/05 que el vacío dejado por el legislador debe ser llenado de acuerdo con los criterios auxiliares del derecho, y no "caprichosamente" por el juez, todo ello para proteger el derecho al trabajo en beneficio del más débil en la relación: el pensionado. Se remite a la analogía para establecer como criterio claro para la indexación de la primera mesada pensional el índice de precios al consumidor (Sentencia C-387, 1994), de igual manera, a pesar que una empresa se encuentre en proceso de liquidación, es su deber responder a los pensionados indexando su mesada laboral y en un tiempo de 48 horas debe adelantar todos los trámites para tal fin. Aclarado lo anterior, la Corte fijó la siguiente fórmula matemática:

$\mathrm{R}=\mathrm{Rh}$ índice final

Índice inicial

Según la cual el valor presente de la condena $(R)$ se determina multiplicando el valor histórico $(\mathrm{Rh})$, que es el promedio de lo devengado por el demandante durante el último año de servicios, por el guarismo que resulte de dividir el índice final de precios al consumidor vigente a la fecha a partir de la cual se reconoció la pensión, entre el índice inicial, que es el existente al 27 de enero de 1974" (Sentencia T-806, 2005).

Siguiendo los anteriores parámetros, la Corte ha dicho que se debe pagar los montos adeudados e indexarlos desde ese momento hasta la notificación del pronunciamiento. La sentencia T-098/05 aunque sigue el precedente de la SU120/03, también fija nuevos parámetros, convirtiéndose en hito y confirmadora de línea. En la sentencia T-906/05 se reitera que el derecho a mantener el poder adquisitivo de las pensiones sólo es fundamental por conexidad, ya sea cuando se viola el derecho al mínimo vital que conlleva a la dignidad humana, o cuando se presenta un trato discriminatorio concediendo a algunas personas la indexación y a otras no, estando todas en iguales condiciones respecto a los hechos; de la misma manera afirma que una vez desconocidos los derechos, se debe interponer prontamente la demanda y no dejar pasar mucho tiempo, ya que puede ser causal para negar el amparo.

Posteriormente, en la sentencia C-862/06, la Corte realiza un recuento histórico de las decisiones emitidas por las altas Cortes, además de dar un concepto mucho más amplio de la indexación: "es un sistema que consiste en la adecuación automática de las magnitudes monetarias a las variaciones del nivel de precios, con el fin de mantener constante, el valor real de éstos, para lo cual se utilizan diversos parámetros que solos o combinados entre sí, suelen ser: el aumento del costo de la vida, el nivel de aumento de precios mayoristas, los salarios de los trabajadores, los precios de productos alimenticios de primera necesidad, etc".

También la sentencia C-862 de 2006 hace énfasis en la jurisprudencia emitida por la misma Corte. Ha establecido que la mesada pensional es un mecanismo que garantiza el derecho al mínimo vital, ya que la pérdida de capacidad adquisitiva de la moneda afecta el equilibrio de las prestaciones, y es para subsanar este defecto que 
se presenta la indexación. Dicha sentencia confirma las tres subreglas establecidas con anterioridad: la primera, que las pensiones incluso las que sean iguales al salario mínimo deben ser reajustadas según el IPC; segundo, que así no exista norma explícita que regule la indexación, tampoco existe norma que diga lo contrario, y en este caso es deber del juez por analogía suplir dicho vacío normativo; y por último, que el mantener el poder adquisitivo constante de las pensiones puede llegar a ser un derecho fundamental por conexidad, siendo que la actualización periódica de las mesadas pensionales es una aplicación concreta de los deberes que tiene el Estado con el fin de garantizar los derechos económicos, sociales y culturales consagrados en la Carta Política.

En la sentencia T-1052 de 2008 asegura la Corte Constitucional que todos los pensionados, independientemente del régimen de pensión al cual pertenezcan, tienen derecho al reajuste anual de su pensión. Cuando una persona solicita el traslado de su capital de la cuenta de ahorro a otro fondo de pensiones, el Estado debe respetar los derechos adquiridos por los pensionados y reajustarla de acuerdo con el IPC, si tal situación no se da, la pensión se verá reducida o congelada debido a que pierde su poder adquisitivo, cuestión prohibida expresamente por la Constitución, razón por la cual no se debe negar la indexación. Esta sentencia reitera la jurisprudencia establecida por la misma Corte Constitucional.

Finalmente, la sentencia arquimédica de este análisis, la T-020/11, reafirma que está prohibida la congelación o reducción de la mesada pensional, como ya se había expresado en la sentencia T-1052/08. Como última sentencia del tema, reitera lo dicho por la Corte en anteriores situaciones, aludiendo que el precedente fijado por esta corporación debe ser aplicado a situaciones cuyo contendido fáctico, es decir, los hechos sean similares y a favor del pensionado, quien es la parte débil de la relación de trabajo, pues no tiene los medios para soportar la desvalorización del dinero, y es por ello que se le ha otorgado el derecho constitucional de acceder a la indexación de su primera mesada laboral.

\section{CONCLUSIONES}

> La Corte Constitucional siempre ha manifestado la misma posición respecto al deber de los empleadores en conceder la indexación a sus pensionados. Tan sólo en el 2003, es cuando la Corte varía un poco su línea jurisprudencial, pero dentro de la misma sombra decisional al reconocer la indexación de la primera mesada pensional como un derecho fundamental por conexidad con el derecho a la dignidad humana y el mínimo vital.

La línea jurisprudencial de la Corte Constitucional ha definido que el poder adquisitivo de la pensiones es un derecho constitucional, y en determinadas situaciones puede llegar a considerarse un derecho fundamental por conexidad con el mínimo vital y la dignidad humana y sí bien es cierto que existe un vacío normativo en el tema de la indexación, este no es pretexto para negarla, ya que en tal caso le compete al juez dar solución a la situación. 
D Es deber de las altas cortes unificar su jurisprudencia, no sólo al interior de cada una de ellas, sino en relación con las demás, con el objetivo de sentar preceptos claros y no crear incertidumbre tanto en los demandantes como en los jueces, por este motivo fue que se dio inicio a esta narración jurisprudencial, planteando como fin general el análisis de las decisiones tanto de la Corte Suprema de Justicia como de la Corte Constitucional.

\section{REFERENCIAS BIBLIOGRÁFICAS}

- www.corteconstitucional.gov.co

- López Medina, D. (2006). El derecho de los jueces. Bogotá: segunda edición. 366 págs. 